Supplement of Atmos. Chem. Phys., 19, 1685-1702, 2019

https://doi.org/10.5194/acp-19-1685-2019-supplement

(c) Author(s) 2019. This work is distributed under

the Creative Commons Attribution 4.0 License.

(c) (1)

Supplement of

\title{
Biomass-burning smoke heights over the Amazon observed from space
}

\section{Ralph A. Kahn}

Correspondence to: Laura Gonzalez-Alonso (lgonzalezalonso1@ @ sheffield.ac.uk)

The copyright of individual parts of the supplement might differ from the CC BY 4.0 License. 
Table S1. Summary of main features for instruments and products used in the study.

\begin{tabular}{|c|c|c|c|c|c|c|c|}
\hline \multirow[b]{2}{*}{ Parameter } & \multirow{2}{*}{$\begin{array}{l}\text { Instrument/ } \\
\text { Product }\end{array}$} & \multirow{2}{*}{$\begin{array}{c}\text { Satellite }^{a} / \\
\text { Model }\end{array}$} & \multirow{2}{*}{$\begin{array}{l}\text { Level/ } \\
\text { Version }\end{array}$} & \multicolumn{2}{|c|}{ Spatial Resolution } & \multirow[b]{2}{*}{ Temporal Res. } & \multirow[b]{2}{*}{ Main reference } \\
\hline & & & & Horizontal & Vertical & & \\
\hline Smoke Height & MISR & Terra & Level $1 \& 2$ & $275-500 \mathrm{~m}$ & $1.1 \mathrm{~km}$ & variable & Diner et al., (1998) \\
\hline Aerosol Extinction & CALIOP & CALIPSO & Level 2/v4 & $30-60 \mathrm{~m}$ & $333 \mathrm{~m}$ & variable & Winker et al., (2013) \\
\hline Active Fires & MOD14/MYD14 & Terra \& Aqua & v6 & $1 \mathrm{~km} \times 1 \mathrm{~km}$ & & daily & Giglio at al., (2003) \\
\hline Land Cover & MOD12Q1 & Terra \& Aqua & v5.1 & $500 \mathrm{~m} \times 500 \mathrm{~m}$ & & annual & Friedl et al., (2010) \\
\hline PBL & MERRA-2 & GEOS-5 DAS & v5.12.4 & $0.625^{\circ} \times 0.5^{\circ}$ & 42 & hourly & Bosilovich et al., (2015) \\
\hline Atm. Stab. & MERRA-2 & GEOS-5 DAS & v5.12.4 & $0.625^{\circ} \times 0.5^{\circ}$ & 42 & 6-hourly & Bosilovich et al., (2015) \\
\hline drought (DSI) & MOD16/MOD13 & Terra \& Aqua & & $0.05^{\circ} \times 0.05^{\circ}$ & & 8-day & Mu et al., (2013) \\
\hline
\end{tabular}

${ }^{a}$ Satellite swaths are $380 \mathrm{~km}$ (MISR), $2330 \mathrm{~km}$ (MODIS) and $70 \mathrm{~m}$ (CALIOP), with overpass times over the Amazon as 10-11 LT (AM/PM) (Terra), 1-2 LT (AM/PM) (Aqua) and 1:30 LT (AM/PM) (CALIPSO) 
Table S2. Statistical summary for main smoke plume and plume rise controlling parameters ${ }^{a}$.

\begin{tabular}{|c|c|c|c|c|c|c|c|c|c|c|c|c|}
\hline & \multicolumn{4}{|c|}{ Tropical Forest } & \multicolumn{4}{|c|}{ Savanna } & \multicolumn{4}{|c|}{ Grassland } \\
\hline & \multicolumn{2}{|c|}{ Dry Years $b$} & \multicolumn{2}{|c|}{ Wet Years $b$} & \multicolumn{2}{|c|}{ Dry Years } & \multicolumn{2}{|c|}{ Wet Years } & \multicolumn{2}{|c|}{ Dry Years } & \multicolumn{2}{|c|}{ Wet Years } \\
\hline & Early ${ }^{c}$ & Late $^{c}$ & Early & Late & Early & Late & Early & Late & Early & Late & Early & Late \\
\hline Smoke Height (m) & $698 \pm 407$ & $898 \pm 451$ & $906 \pm 418$ & $1180 \pm 693$ & $795 \pm 462$ & $1110 \pm 589$ & $984 \pm 473$ & $1250 \pm 653$ & $881 \pm 508$ & $1160 \pm 474$ & $1280 \pm 971$ & $1350 \pm 728$ \\
\hline FRP (MW) & $182 \pm 408$ & $245 \pm 613$ & $369 \pm 813$ & $369 \pm 813$ & $352 \pm 744$ & $503 \pm 828$ & $269 \pm 456$ & $330 \pm 537$ & $390 \pm 480$ & $567 \pm 838$ & $148 \pm 152$ & $529 \pm 654$ \\
\hline $\mathrm{AOD}$ (unitless) & $0.53 \pm 0.29$ & $0.73 \pm 0.37$ & $0.21 \pm 0.17$ & $0.33 \pm 0.21$ & $0.37 \pm 0.30$ & $0.46 \pm 0.32$ & $0.14 \pm 0.12$ & $0.28 \pm 0.18$ & $0.29 \pm 0.26$ & $0.58 \pm 0.35$ & $0.1 \pm 0.07$ & $0.30 \pm 0.15$ \\
\hline Stability $(\mathrm{K} / \mathrm{km})$ & $5.27 \pm 3.64$ & $4.28 \pm 2.82$ & $3.93 \pm 2.17$ & $3.11 \pm 1.76$ & $4.17 \pm 3.72$ & $2.92 \pm 2.95$ & $3.44 \pm 3.24$ & $2.47 \pm 2.26$ & $2.45 \pm 3.07$ & $2.32 \pm 1.92$ & $3.15 \pm 3.65$ & $2.07 \pm 1.53$ \\
\hline PBL Height $(\mathrm{m})$ & $1330 \pm 535$ & $1290 \pm 551$ & $1150 \pm 487$ & $1220 \pm 486$ & $1580 \pm 509$ & $1510 \pm 482$ & $1350 \pm 522$ & $1480 \pm 543$ & $1760 \pm 525$ & $1770 \pm 534$ & $1360 \pm 443$ & $1380 \pm 316$ \\
\hline Number & 536 & 438 & 238 & 271 & 434 & 575 & 353 & 516 & 51 & 43 & 17 & 38 \\
\hline
\end{tabular}

${ }^{a}$ Reported the average \pm SD for smoke plumes with valid values for all the parameters

${ }^{b}$ Dry years are 2005, 2007 and 2010 and wet years are 2006, 2008, 2009, 2011 and 2012

${ }^{c}$ Early season is defined as July-August and late season as September-November 

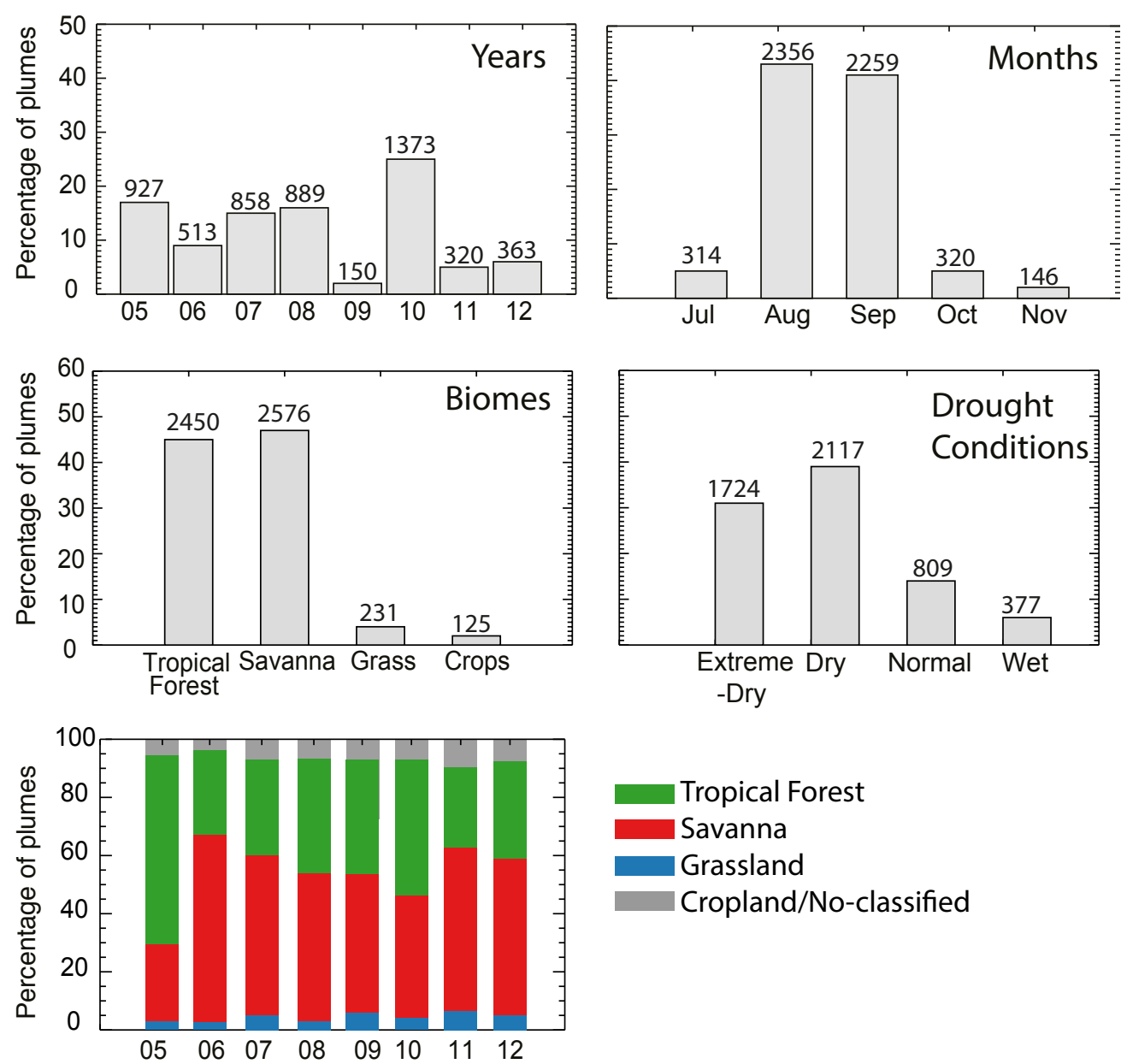

Figure S1. Percentage of MISR plumes in the climatology classified by year, month, biome and drought conditions. Absolute values in each distribution are included above the bars. Percentage of MISR plumes classified by biome and year are also shown, as tropical forest (green), savanna (red), grassland (blue), and cropland and not classified (grey). 


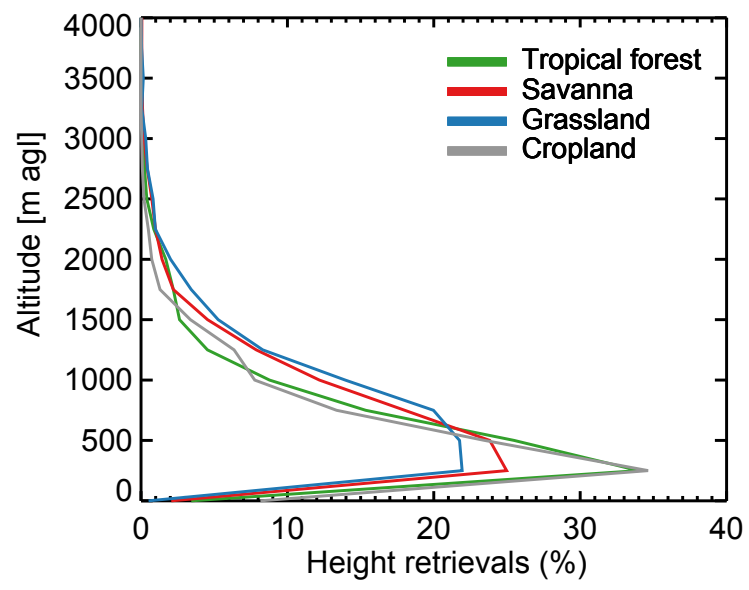

Figure S2. Vertical distribution of individual MISR stereo-height retrievals, averaged over all plumes in the eight-year of the study and stratified by biome. 

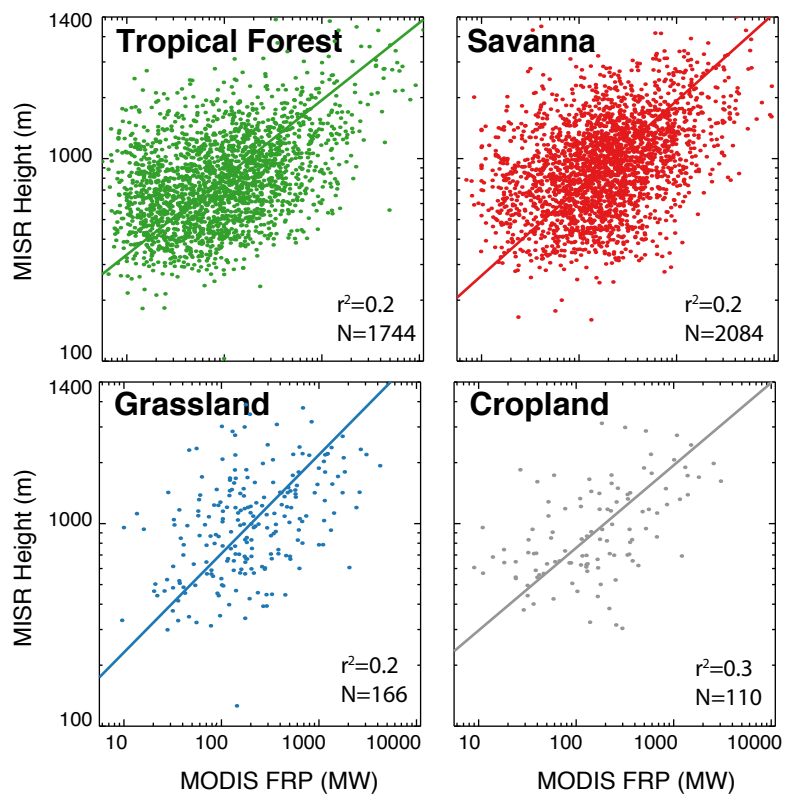

Figure S3. Relationship between MISR maximum plume heights and MODIS total fire radiative power (FRP) for the 8-year data set. Data are colour-coded per biome as tropical forest (green), savanna (red), grassland (blue), and cropland (grey). Total number of observations and $r^{2}$ are given in the annotation of each panel. 

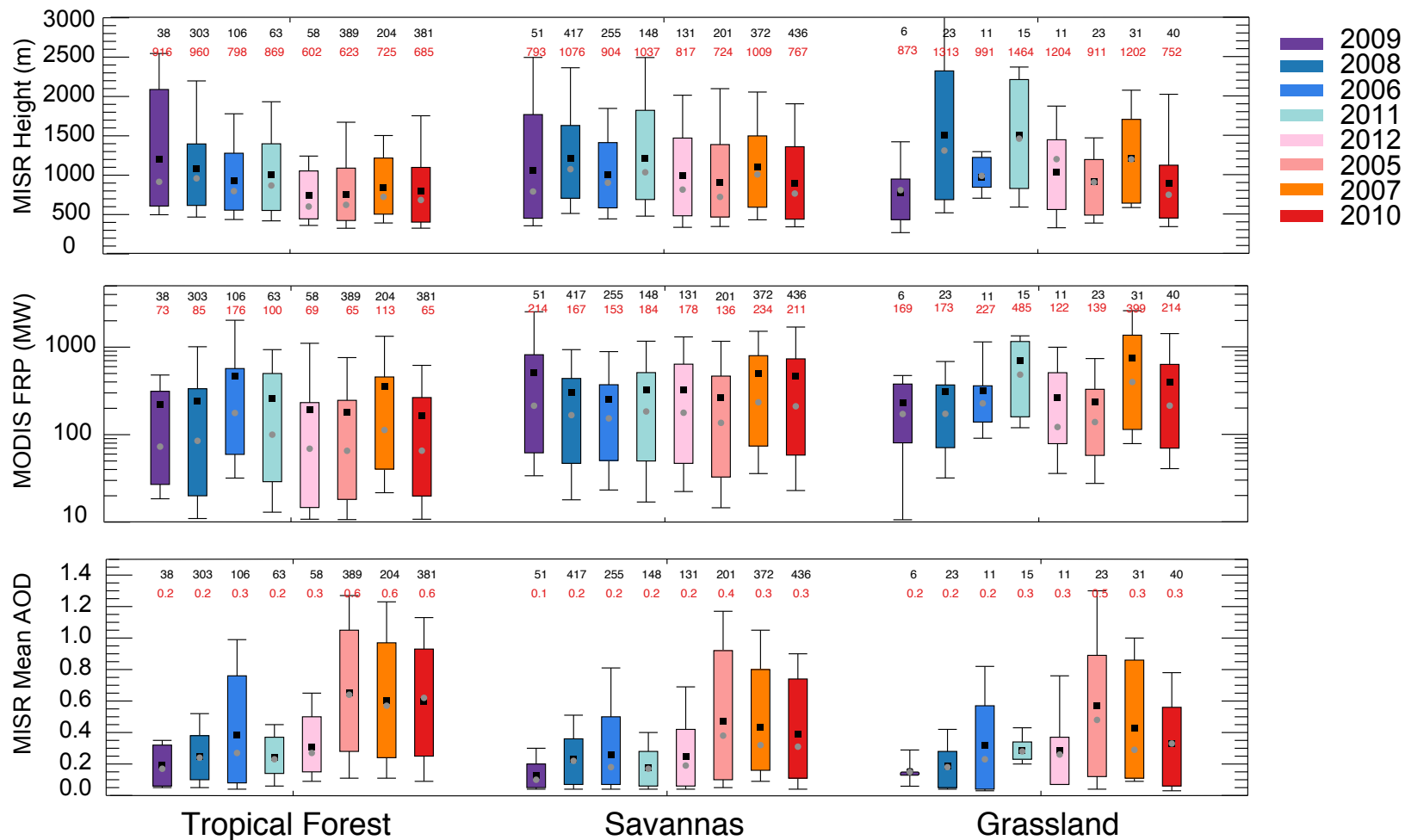

Figure S4. Interannual variability of MISR plume maximum heights above the terrain, MODIS FRP and MISR AOD by biome. Bar plots indicate the distribution of the data for each year. Bars in this figure are ordered based on DSI (Table 3) rather than chronologically, The medians (grey circles) and the means (black squares) are shown along with the central 67\% (box) and the central 90\% (thin black lines). Distributions are colour-coded based on drought conditions (Table 3). Note that, although no MODIS DSI data are available for year 2012, this year is plotted in the middle as it is defined as dry year by Erfanian et al., (2017). The number of observations (in black) and the median values (in red) included in each distribution are given at the top of the plot. 


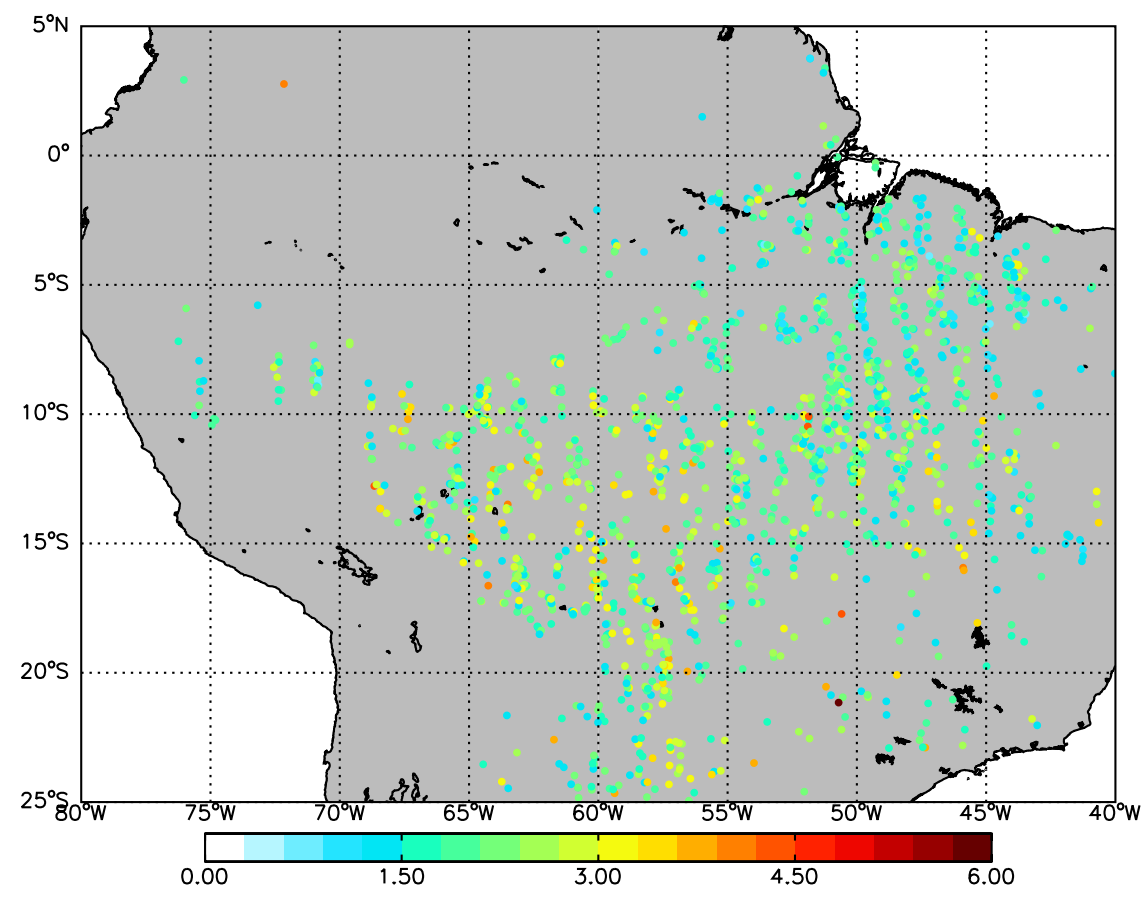

Figure S5. Location of the CALIOP plumes analysed with the median smoke plume height over the Amazon domain. 

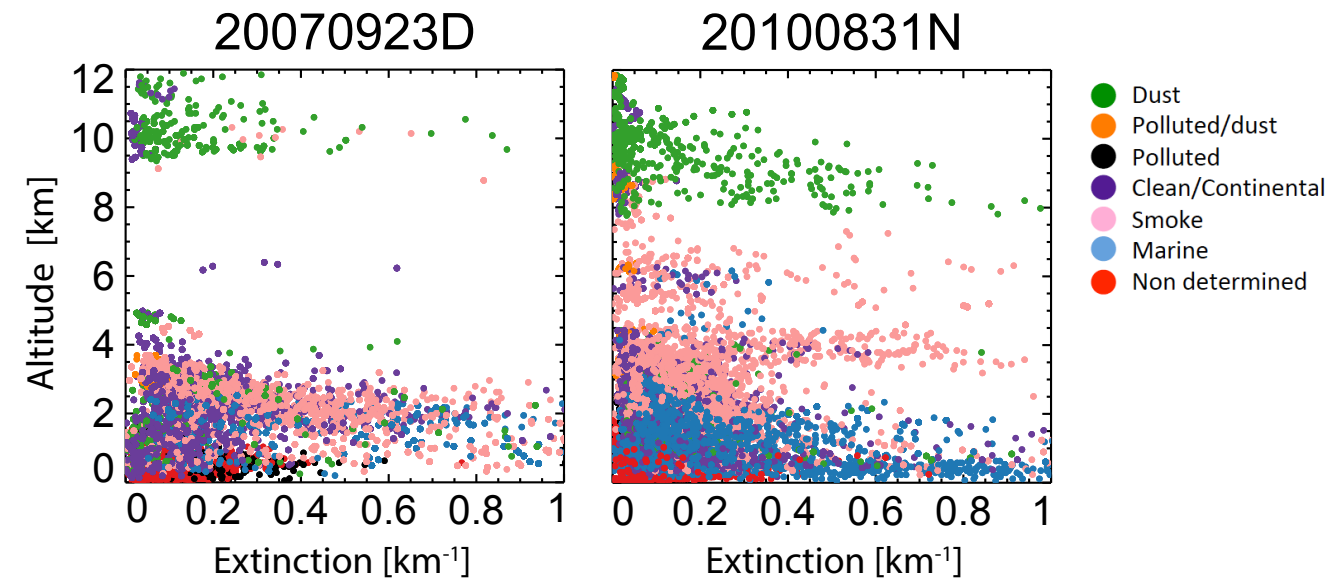

Figure S6. Examples of CALIOP vertical extinction profiles with smoke aerosols above $6 \mathrm{~km}$. Values are coloured by classified aerosol types. Profile 20070923D represents a case where high altitude smoke is disconnected from low altitude smoke and profile 20100831N gives an example of smoke gradually distributed from low to high altitudes. 